\title{
Good News
}

Rosemary S. A. Shinkai

Editor-in-Chief
$\mathrm{T}$ The Revista Odonto Ciencia (Journal of Dental Science) has the privilege of publishing the second guest editorial of the 2010 special series on science transfer. Dr. Marli Elisabeth Ritter dos Santos, from the Pontifical Catholic of Rio Grande do Sul, gives us an introduction to the bases of technology transfer from academia to industry and its impact on university management. This guest editorial focuses on the interaction of academics, industry and government to achieve innovative applied research with possible high impact for society. Although dental clinics and basic research have always used commercial products and equipment as well as standardized procedures, many dental researchers still remain unfamiliar with the operational process for developing joint venture projects leading to possible intellectual property features. This approach has been increasingly supported by substantial grants from the main funding agencies worldwide, and it is included in the international agenda of research priorities. We hope this guest editorial helps our community to reflect on the ultimate usage of all research performed with public and private funding to improve both the quality of life and socioeconomic development of society.

This issue also has the pleasure of reproducing the press release announcement of the 2010 Yngve Ericsson Prize for Research in Preventive Odontology. This prize has been granted to Dr. Jaime Aparecido Cury, from the University of Campinas, Brazil, for his studies on the prevention of dental caries and fluoride. Known as the Nobel Prize of Preventive Dentistry, this distinction was awarded to a Latin-American researcher for the first time. We would like to thank Professor Anders Linde, from the Sahlgrenska Academy at Göteborg University and president of the Swedish Patent Revenue Fund, for sending the material to be reprinted in our dental journal.

Finally, we would like to congratulate the Journal of Applied Oral Science and its editor-in-chief, Dr. Carlos Santos from the University of São Paulo Bauru Dental School, for the recent inclusion in the Journal of Citation Reports from the Web of Science. This journal is the first Ibero-American dental journal indexed in that database with an impact factor by Thomson Reuters. We hope that this particular achievement and other important events give more visibility to scientific dental publications from developing countries, reflecting the increasing relative contribution of research from different parts of the world toward building relevant global knowledge about oral healthcare and education. 


\section{if Patentmedelsfonden \\ OO för Odontologisk Profylaxforskning}

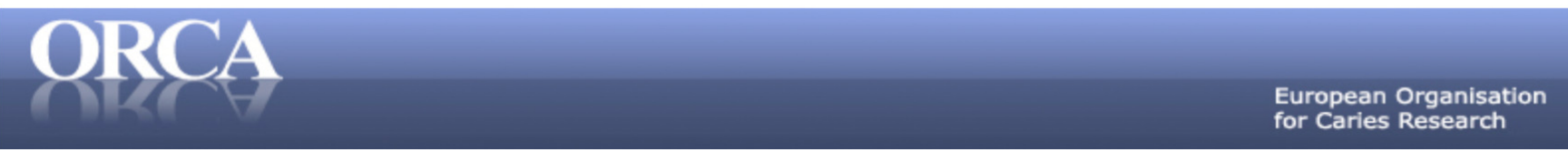

Progress in prophylactic dentistry research awarded

The 2010 Yngve Ericsson Prize for Research in Preventive Odontology has been awarded jointly to Professor Jaime A. Cury, Piracicaba, Brazil and Professor Hannu Hausen, Oulu, Finland. The Prize of 400000 SEK (42000€) is to be shared equally between the two recipients and will be awarded at the ORCA Congress in Montpellier.

Jaime A. Cury is Professor of Biochemistry and Cariology at the Piracicaba Dental School, University of Campinas, Brazil. Professor Cury has given valuable contributions to an increased understanding of the caries process, particularly to its prevention, through his research into the importance of different fluoride sources, and has devoted much of his efforts to studies on dental plaque (the cariogenic dental biofilm) as well. Dr. Cury has a persistent commitment to health-promoting research, among which could be mentioned a particular interest in the mechanisms of fluoride delivery systems responsible for the caries decline. His contribution to the scientific development in caries-related research, an important role in the establishment of caries-preventive policies, as well as his function as an opinion leader, have helped Brazil to experience a signicant decrease in caries prevalence in the last decades.

Hannu Hausen is Professor in Community Dentistry at the Institute of Dentistry, University of Oulu, Finland. Professor Hausen is a recognized expert in the field of oral health promotion, who has devoted his efforts and research activities to promoting oral health especially among children and adolescents. With behavioral science as an important ingredient, Dr. Hausen has focused his research to the epidemiology and control of dental caries, and he has been one of the pioneers to strengthen the concept of a multisectorial and common risk factor approach. His most cited articles have shown that even intensive preventive activities provided in dental clinics do not improve the oral health of children with high caries risk, if they are applied in a context where no population-based oral health promotion takes place. Professor Hannu Hausen has a rare ability to identify and investigate important problems as well as to make use of the findings in society.

The Yngve Ericsson Prize, previously known as The Patent Revenue Fund's Prize for Research in Preventive Odontology, is awarded once every 3 years in acknowledgement of outstanding contributions to prevention of oral diseases. Established in 1963, The Swedish Patent Revenue Fund for Research in Preventive Odontology was originally founded on royalties from patents, primarily patents for addition of fluoride to dentifrices to prevent or arrest dental caries. The Fund is the largest non-public granting source for dental research in Sweden through its continued support of research into prevention of dental and oral diseases.

The Prize awardees have been selected by a five-member Prize Committee appointed by the Patent Revenue Fund and ORCA - the European Organization for Caries Research. The Prize will be presented on July 8, 2010 at the ORCA Congress in Montpellier, France.

For further information, please contact:

Anders Linde, Professor at the Sahlgrenska Academy, University of Gothenburg, Sweden, President of the Patent Revenue Fund and Chairman of the Prize Committee. Telephone: +46-31-786 3386; E-mail: linde@odontologi.gu.se

Nigel Pitts, Professor at the University of Dundee, Scotland, Immediate Past President of ORCA and Member of the Prize Committee. Telephone: +44-1382-420067; E-mail: n.b.pitts@chs.dundee.ac.uk

Paul Tramini, Professor at the Faculté d'Odontologie de Montpellier, France, and Co-President for the 2010 ORCA Congress in Montpellier. Telephone: +33-4-6765 9553; E-mail: paul.tramini@orange.fr

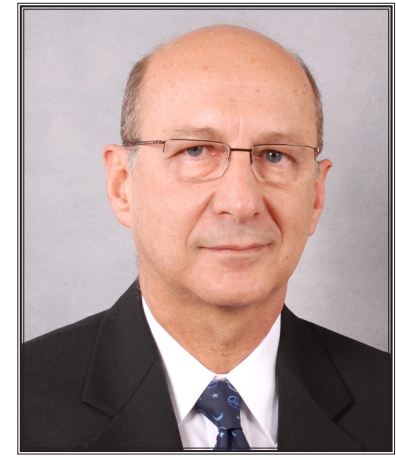

Professor Jaime A. Cury

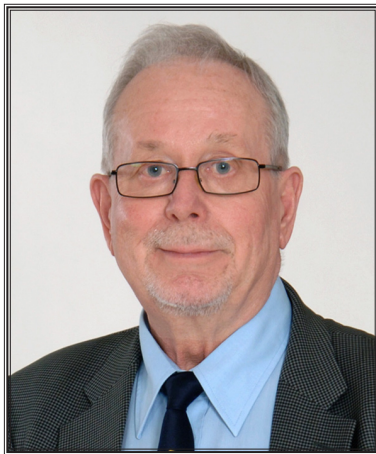

Professor Hannu Hausen 